\title{
Changes in the geomagnetic field has little effect on the overwintering range of Eastern North American fall migratory monarch butterflies (Danaus plexippus), indicating a lack of an innate magnetic map sense for navigation
}

Patrick Anthony Guerra ( $\sim$ patrick.guerra@uc.edu ) University of Cincinnati

Stephen Matter University of Cincinnati

\section{Research}

Keywords: Monarch butterfly, migration, magnetic map sense, displacement study, overwintering, Mexico Posted Date: February 3rd, 2020

DOI: https://doi.org/10.21203/rs.2.22446/v1

License: (c) (1) This work is licensed under a Creative Commons Attribution 4.0 International License. Read Full License 


\section{Abstract}

\section{Background}

Individuals of many species that perform annual long-distance migrations are capable of stopping at specific overwintering destinations, despite having not been there before. The iconic monarch butterfly (Danaus plexippus) and its annual long-distance fall migration is a famous example of this phenomenon. During the fall, Eastern North American monarch butterflies use various compass mechanisms to properly orient their flight southwards, in order to leave their summer breeding grounds in Southern Canada and the Northern United States, and reach their overwintering sites in Central Mexico. It remains a mystery, however, how monarchs locate and stop at these specific, consistent overwintering sites, especially since these individuals are on their maiden voyage.

\section{Methods}

We test the hypothesis that fall migrant monarchs locate these overwintering sites by using an innate, inherited map sense based on sensing and responding to specific geomagnetic signatures that are correlated with the overwintering sites. Using a natural displacement approach, we examined if the locations of overwintering sites and the abundance of monarchs at them, changes with the natural shift of the Earth's magnetic field over time (2004-2018).

\section{Results}

We found that despite the natural displacement of the geomagnetic field over the years, the locations of the overwintering sites and monarch abundance were unaffected. For example, fall monarchs continued to overwinter at the most southern sites in Mexico, even when the geomagnetic coordinates associated with these sites would have shifted north due to the natural shift of the Earth's magnetic field, placing these sites significantly outside the range of the overwintering area.

\section{Conclusions}

Our results suggest that monarchs do not employ a map sense based on geomagnetic cues for finding their overwintering sites, and might instead use other mechanisms or strategies for locating them (potentially using localized sensory cues) once they are near or have arrived in Central Mexico. We suggest that future work should now focus on understanding what these cue parameters are, in order to inform conservation efforts that are aimed at protecting the threatened monarch butterfly and preserving its annual long-distance migration.

\section{Background}

Individuals of many species use cues derived from their environment to facilitate ecologically important goal-directed movement within the landscape. The long-distance fall migration of the iconic monarch butterfly, Danaus plexippus (Lepidoptera; Nymphalidae), is a spectacular example of goal-directed animal 
movement phenomena during which individuals use environmental sensory cues to guide them during their long journey, in order to reach their goal destination [1, 2]. During the fall, millions of Eastern North American monarchs leave their summer breeding grounds in Southern Canada and the Northern United States, and migrate to a handful of select overwintering sites high atop a few mountain ranges in Central Mexico $[3,4]$.

Fall migrant monarchs have previously been shown to use sensory-based compass mechanisms to maintain the proper southwards flight orientation during the fall migration [2]. The dominant compass used by monarchs is the time-compensated sun compass $[5,6,7]$. Monarchs use the sun as a skylight visual cue to maintain the proper southwards flight heading. Given the sun's apparent change in position in the sky throughout the day due to the Earth's daily rotation about its axis, monarchs use their internal circadian clock as a timing mechanism to compensate for the sun's movement, in order to properly use the sun as a directional cue throughout the fall migration. On cloudy days when directional daytime skylight cues are unavailable, e.g., overcast conditions, migrants can use a magnetic compass as a backup mechanism for southwards directionality [8]. Monarchs use the inclination angle of the Earth's magnetic field that co-varies predictably with latitude, as another directional cue for flying southwards. Although these compasses can be used for maintaining proper flight directionality, monarchs cannot use these mechanisms for locating and stopping at the overwintering sites, as they only allow monarchs to orient in the direction of their goal destination. It remains a great mystery as to how naïve fall migrant monarchs on their maiden flight, find the same overwintering grounds year after year.

It is possible that monarchs use a map sense for locating the overwintering sites. A map sense allows monarchs to know both the direction that they should fly in and their respective geographic location relative to their goal $[2,9]$. This map sense most likely consists of a genetically imprinted "overwintering site" location, as fall monarchs reaching the overwintering sites have never been there before. One type of map sense possessed by long-distance migrants is that of a geomagnetic map sense [9], as demonstrated by long-distance migratory animals such as sea turtles [10], birds [11], salmonid fish [12], eels [13], newts [14], and spiny lobsters [15]. The innate map sense of naïve individuals on their first migratory journey (and only southwards migratory journey for fall monarchs) is hypothesized to rely on the recognition of specific regional and site-specific geomagnetic conditions (e.g., bicoordinate map coordinates based on inclination angle and total intensity; [10]) that serve as geomagnetic cues or signposts on a magnetic map that can lead individuals to the approximate location of their goal destination. These geomagnetic conditions can also elicit specific behavioral responses that then allow individuals to find their actual goal destination, a finely-tuned process which might rely on sensing other environmental cues that are correlated with these geomagnetic map signatures, or that are present at the geographical locations indicated by these geomagnetic conditions $[9,10]$. Therefore, in addition to using magnetic cues for southwards flight directionality, fall migrant monarchs may therefore use their magnetic sense to recognize the geomagnetic signatures of the overwintering sites as part of an inherited magnetic map sense for locating the small number of overwintering sites in Mexico [2]. The possibility that monarchs possess a map sense remains controversial $[16,17,18]$. 
To test for a geomagnetic map sense, researchers have used displacement trials. Here, individuals are physically displaced to unfamiliar, geographical locations to determine if they will adjust their behavior to correct for the displacement, e.g., $[15,19,20]$. Alternatively, animals have been tested in simulated magnetic displacement experiments. These studies subject individuals to artificially generated magnetic fields of locations that are different from the testing site and the behavior of individuals is monitored for the expression of predicted responses or for any changes in behavior, e.g., a change in orientation behavior relative to what is observed or expected at a control site [10]. A similar, but less frequently used method for testing for the existence of a geomagnetic map sense is to examine the behavior of animals in response to the Earth's shifting magnetic field over time, i.e., secular variation of the geomagnetic field [21]. This approach examines the behavior of individuals in response to the natural displacement of the Earth's magnetic field under natural conditions over time.

In this study, we used a natural experiment, the change in the Earth's magnetic field from 2004 to 2018 , to test the provocative hypothesis that $D$. plexippus uses innate responses tuned to specific geomagnetic cues to facilitate map sense navigation to a specific location, i.e., the overwintering sites in Central Mexico. We hypothesize that if $D$. plexippus navigates to specific locations based on an innate magnetic map sense, that there should be a progressive shift in the overwintering range from southern to northern sites, as monarchs track the decreases in the intensity and inclination angle of the magnetic field over time. As the geomagnetic parameters associated with the geographical locations of the overwintering sites have naturally shifted northwards, monarchs should adjust where they stop in Mexico and where they form overwintering aggregations, if they rely exclusively or predominantly on an innate magnetic map sense calibrated to specific geomagnetic signatures. Alternatively, if monarchs do not respond to changes in the Earth's magnetic field, e.g., they continue to overwinter in geographical locations that now possess significantly different geomagnetic signatures due to the shifting geomagnetic field, this would indicate that they do not have a map sense navigation system that relies on responding to specific geomagnetic signatures in Mexico for finding the overwintering sites. This would suggest that monarchs might then rely on other cues for stopping at the overwintering sites once they are nearing or are in Mexico $[9,21]$.

\section{Methods}

\section{Fall Migration of Eastern North American Monarchs}

We used data on the areal extent of overwintering colonies in Mexico collected by the World Wildlife Foundation funded Biosfera Mariposa Monarcha, each December since 2004. During each year, workers there determine the area occupied by one or more overwintering colonies at each site by walking the perimeter of forest that encompasses each colony. They record GPS coordinates and determine the area occupied by each colony using GIS. They sum the areas of each colony to determine the total area for each overwintering site. The total area is used as an estimate of relative yearly abundance $[22,23,24,25]$. For this study, we examined data from 2004-2018 for twelve sites that have been consistently sampled 
since $2004[26,27,28,29,30,31,32,33,34,35,36,37,38,39,40]$. We used the earliest estimate in cases where butterflies were sampled multiple times.

It is unclear how much the magnetic field has changed at these sites over this time. We calculated the magnetic field at each site based on the International Geomagnetic Reference Field (IGRF-12), which provides historical data based on date, latitude, and longitude, since 1900. We calculated the magnetic field for each site on November $15^{\text {th }}$ of each year. This date corresponds to the midpoint of the arrival of migrants, with monarchs typically arriving at the overwintering sites around November $1^{\text {st }}$ (the Day of the Dead celebrations) [2].

We quantified the change in the magnetic field at each site, for each year. We related the magnetic field to the area occupied by overwintering butterflies (relative abundance) with the expectation that, if monarchs use the magnetic field to locate specific overwintering sites in Mexico (i.e., parameters of the Earth's magnetic field at those sites, such as inclination angle and field strength, either together or separately), there would be a change in abundance at these sites equal to the change in magnetic field. As the change in magnetic inclination and field intensity were highly correlated at each site over the 14 years $(r<0.99)$, we simply used magnetic inclination in analyses, as either would be redundant when analyzed together.

\section{Results}

Since 2004, magnetic inclination values across the 12 monarch overwintering sites in Central Mexico have decreased by an average of $0.173 \pm 0.003^{\circ}$. Similarly, the intensity of the magnetic field has decreased by an average of $1264 \pm 1.519 \mathrm{nT}$. The magnitude of these changes in geomagnetic field parameters is equivalent to moving approximately $30 \mathrm{~km}$ north. Such a shift should have moved the three most southern overwintering sites significantly out of the overwintering range, with the specific geomagnetic signatures indicating that these particular geographical sites displaced northwards (Figure 1). If the butterflies use the parameters of the Earth's magnetic field at the overwintering sites as constant cues for navigating towards and locating these sites, then monarch abundance at the three most southern overwintering sites should decline over time, the sites would cease to be used for overwintering, or both would happen simultaneously (Figure 1).

We found no evidence to support the hypothesis that monarch butterflies use the geomagnetic field as part of a map sense to locate specific overwintering sites in Mexico. In only one case, Lomas de Aparicio, was there a significant relationship between the estimated abundance of the overwintering colony and the decrease in magnetic inclination. Overall, our analysis shows that monarchs did not alter their overwintering behavior in response to the northwards displacement of the geomagnetic signatures of overwintering sites. Furthermore, the three most southerly sites that should be outside of the overwintering range in 2018 (Figure 1), showed an increase in monarch abundance in relation to the general decrease in both the inclination angle and intensity of the geomagnetic field (Figure 2). Finally, across all sites, there was no trend for a south to north increase in abundance in overwintering monarchs, 
which would be consistent with monarchs sensing and tracking the changes in the geomagnetic signatures of the overwintering sites over time (Figure 3).

\section{Discussion}

The results from our natural displacement study are inconsistent with fall monarch butterflies exclusively relying on, or possessing, an innate map sense calibrated for responding to specific geomagnetic signatures for locating the same overwintering sites in Mexico year after year. Monarchs did not adjust their selection of overwintering locations in Mexico nor their abundance at these specific sites, in concordance with the natural displacement (shift) of the Earth's magnetic field over time, during the span of years that we examined. Despite occurring on a different time scale, this natural displacement of the geomagnetic signatures of the monarch overwintering sites $30 \mathrm{~km}$ away from their original locations over time is consistent with distances that have been used in displacement studies (i.e., within the same magnitude range), but that elicited a clear response and that revealed an obvious map sense in other species, e.g., displacement distances ranging from $10 \mathrm{~m}$ to $45 \mathrm{~km}$ tested for alligators [41], newts [42], spiny lobsters [43], Burmese pythons [44], and intertidal fish [45]. Moreover, although it is likely to be less accurate and possess limited magnetic resolution [46], it is also unlikely that monarchs possess a crude map sense that instead responds to a suite of geomagnetic cues representative of a significantly larger and more general target area that encompasses all of the overwintering sites, since monarchs continued to establish themselves in large numbers at sites that ended up outside the general overwintering area in Central Mexico that shifted over time (Figure 1). Here, monarchs continued to establish themselves in overwintering roosts at sites whose geomagnetic parameters had been displaced due to the natural shift in the geomagnetic field. Our results are therefore in stark contrast to the map sense behavior observed in individuals of long-distance migratory species that appropriately adjust their behavior in response to alterations in the magnetic cues that they are exposed to, either in direct displacement studies or in experiments during which individuals are presented with artificially generated magnetic cues to simulate displacement. More importantly, our results suggest that monarchs are likely not true navigators since they do not possess a map sense, at least when considering the use of geomagnetic cues for navigation.

How then might naïve fall migratory monarchs locate their overwintering sites each year? It seems likely that monarchs do use an inherited migration strategy, but one that is tiered [9], in which individuals first simply fly southwards in order to reach the general area in Mexico that encompasses the overwintering sites. Fall monarchs could achieve this by using their compass mechanisms (e.g., the time-compensated sun compass and inclination-based magnetic compass) to continue flying south during migration. Once near the overwintering sites in Mexico, monarchs can shift to secondary and tertiary migration strategies in which they might then use short-range or localized site-specific cues, respectively, for recognizing and locating the overwintering sites themselves $[9,21]$. It has been hypothesized that fall migrant monarchs might locate the overwintering sites by using beacon cues such as olfactory cues (e.g., olfactory cues left by previous monarchs from past fall generations or volatiles from the trees that monarchs overwinter on), or select locations that present the correct microclimate for overwintering, once in Mexico $[2,9]$. 
The use of olfactory cues, in particular cues associated with the trees used for overwintering, seems unlikely for locating the overwintering sites, since fall migratory monarchs in North America do not all overwinter at locations with the same types of host plants. For example, Western North American monarchs, individuals that are genetically equivalent to Eastern North American monarchs [47] and that similarly migrate southwards during the fall, migrate to overwintering sites along the California coast which contain different trees used for overwintering, e.g., introduced eucalyptus trees in California versus oyamel firs in Mexico (albeit it is possible that these different tree species at the different overwintering sites might share common volatile cues). In addition, fall monarchs that overwinter at either Mexican or Californian locations stop at sites that differ in elevation (high-elevation mountains in Mexico versus sites at sea level in California), as well as in their specific geomagnetic signatures. Field studies with fall migratory monarchs in Arizona found individuals that were caught, tagged, and released at the same location and on the same day, at overwintering sites in both California and Mexico [48]. These different observations with fall monarchs from Arizona further support the lack of an inherent map sense for locating suitable overwintering sites, based on innate sensing of specific geomagnetic signatures.

One possible mechanism that both Eastern and Western North American fall monarchs might use for locating the overwintering sites is that individuals from both populations search for the same suitable overwintering microclimate conditions. These specific microclimates might simultaneously occur at multiples places even when they have different habitat conditions, e.g., differences in host vegetation, elevation, and geomagnetic signature. One important aspect of these specific microclimates is the temperature during the overwintering period at these sites; these temperatures are crucial for the survival of monarchs $[49,50]$. Indeed, the temperatures at both Mexican and Californian overwintering sites share similar cold temperatures that can maintain the lower metabolic rates of butterflies such that they can survive on their fat stores till the next spring, are not so cold that individuals will die of freezing, and produce cold conditions that can recalibrate the time-compensated sun compass for northwards oriented flight during the spring remigration [51]. One caveat to the use of this mechanism is that fall monarchs roost nightly during the journey southwards, presumably looking for microclimate conditions conducive to survival at night during fall migration. As monarchs that overwinter in either Mexico or California are functionally forming long-term roosts similar to their nightly roosts during the trip south, it is still unclear why monarchs do not keep flying southwards past these overwintering areas. One possibility is that fall monarchs only migrate within a specific time window during the season, a process mediated by a sensory cue that helps control the progression of the migration (e.g., sun angle at solar noon; [52]). Once outside this temporal window, a situation that can coincide with the overall timing of arrival in Mexico, monarchs may no longer receive relevant sensory input that helps drive continued southwards flight, or the loss of such cues activates other sensory processes (or suppresses them) for finding the overwintering sites using other cues.

\section{Conclusions}

Our study demonstrates that fall migrant monarch butterflies do not possess a map sense based on geomagnetic cues for finding and stopping at the same specific overwintering sites in Central Mexico, 
year after year. This suggests that the choice of overwintering locations by monarchs is not wedded to specific geographical areas. Currently identified overwintering sites are significantly threatened due to deforestation, primarily via illegal logging $[53,54,55]$. If these current sites become sufficiently degraded, our results suggest that monarchs are likely able to find alternative overwintering locations based on cues that might also be present at multiple sites, outside of those that are currently being used or that have been identified. In order to choose and stop at overwintering sites when flying south, migrant monarchs likely use short-range cues that are present in Mexico, e.g., a location with suitable microclimatic conditions. Future work addressing this possibility is now crucial, and can inform conservation efforts aimed at identifying and preserving areas that present such cues and conditions, or to create new overwintering sites possessing these parameters in order to attract migrating monarchs.

\section{Declarations}

\section{Ethics approval}

Not applicable.

\section{Consent for publication}

Not applicable.

\section{Availability of data and materials}

All data generated or analyzed during this study are included in this published article.

\section{Competing interests}

The authors declare that they have no competing interests.

\section{Funding}

Not applicable.

\section{Authors' contributions}

PAG and SFM designed the study. SFM performed the data analysis in this study. PAG and SFM interpreted the results and wrote the manuscript. Both authors read and approved the final manuscript.

\section{Acknowledgements}

Not applicable.

\section{Authors' information}

Not applicable. 


\section{References}

1. Guerra PA, Reppert SM. Sensory basis of lepidopteran migration: focus on the monarch butterfly. Curr Opin Neurobiology. 2015;34:20-28.

2. Reppert SM, de Roode JC. Demystifying monarch butterfly migration. Curr Biol. 2018;28:R1009R1022.

3. Urquhart FA, Urquhart NR. The overwintering site of the Eastern population of the monarch butterfly (Danaus p. plexippus; Danaiidae) in Southern Mexico. J Lepid Soc. 1976;30:153-158.

4. Brower LP. Understanding and misunderstanding the migration of the monarch butterfly (Nymphalidae) in North America. J Lepid Soc. 1995;49:304-385.

5. Perez SM, Taylor OR, Jander R. A sun compass in monarch butterflies. Nature. 1997;387:29.

6. Mouritsen $\mathrm{H}$, Frost BJ. Virtual migration in tethered flying monarch butterflies reveals their orientation mechanisms. P Natl Acad Sci USA. 2002;99:10162-10166.

7. Froy 0 , Gotter AL, Casselman AL, Reppert SM. Illuminating the circadian clock in monarch butterfly migration. Science. 2003;300:1303-1305.

8. Guerra PA, Gegear RJ, Reppert SM. A magnetic compass aids monarch butterfly migration. Nat Commun. 2014;5:4164.

9. Mouritsen $\mathrm{H}$. Long-distance navigation and magnetoreception in migratory animals. Nature. 2018;558:50-59.

10. Lohmann KJ, Putman NF, Lohmann CMF. The magnetic map of hatcling loggerhead sea turtles. Curr Opin Neurobiology. 2012;22:336-342.

11. Wiltschko R, Wiltschko W. Magnetoreception in birds. J R Soc Interface. 2019;16:20190295.

12. Putman NF, Scanlan MM, Billman EJ, O'Neill JP, Couture RB, Quinn TP, et al. An inherited magnetic map guides ocean navigation in juvenile Pacific salmon. Curr Biol. 2014;24:446-450.

13. Naisbett-Jones LC, Putman NF, Stephenson JF, Ladak S, Young KA. A magnetic map leads juvenile European eels to the Gulf Stream. Curr Biol. 2017;27:1236-1240.

14. Phillips JB, Freake MJ, Fischer JH, Borland SC. Behavioral titration of a magnetic map coordinate. J Comp Physiol A. 2002;188:157-160.

15. Boles LC, Lohmann KJ. True navigation and magnetic maps in spiny lobsters. Nature. 2003;421:6063.

16. Mouritsen H, Derbyshire R, Stalleicken J, Mouritsen $0 \varnothing$, Frost BJ, Norris DR. An experimental displacement and over 50 years of tag-recoveries show that monarch butterflies are not true navigators. P Natl Acad Sci USA. 2013;110:7348-7353.

17. Oberhauser KS, Taylor OR, Reppert SM, Dingle H, Nail KR, Pyle RM, et al. Are monarch butterflies true navigators? The jury is still out. P Natl Acad Sci USA. 2013;110:E3680.

18. Mouritsen H, Derbyshire R, Stalleicken J, Mouritsen $0 \varnothing$, Frost BJ, Norris DR. Reply to Oberhauser et al.: The experimental evidence clearly shows that monarch butterflies are almost certainly not true 
navigators. P Natl Acad Sci USA. 2013;110:E3681.

19. Fischer JH, Freake MJ, Borland SC, Phillips JB. Evidence for the use of magnetic map information by an amphibian. Anim Behav. 2001;62:1-10.

20. Wiltschko R. Navigation. J Comp Physiol A. 2017;203:455-463.

21. Lohmann KJ, Putman NF, Lohmann CMF. Geomagnetic imprinting: a unifying hypothesis of longdistance natal homing in salmon and sea turtles. P Natl Acad Sci USA. 2008;105:19096-19101.

22. Calvert WH, Brower LP. The location of monarch butterfly (Danaus plexippus L.) overwintering colonies in Mexico in relation to topography and climate. J Lepid Soc. 1986;40:164-187.

23. Slayback DA, Brower LP, Ramirez MI, Fink LS. Establishing the presence and absence of overwintering colonies of the monarch butterfly in Mexico by the use of small aircraft. Am Entomol. 2007;53:28-40.

24. Vidal O, López-Garcia J, Rendón-Salinas E. Trends in deforestation and forest degradation after a decade of monitoring in the monarch butterfly biosphere reserve in Mexico. Conserv Biol. 2014;28:177-186.

25. Vidal O, Rendón-Salinas E. Dynamics and trends of overwintering colonies of the monarch butterfly in Mexico. Biol Conserv. 2014;180:165-175.

26. Rendón-Salinas E, Galindo-Leal C. Report Preliminar del monitoreo de las coloniasde hibernación de la mariposa Monarca. Reporte de WWF. México D.F. 2004;9pp.

27. Rendón-Salinas E, Valera-Bermejo A, Cruz-Piña M, Rodríguez-Mejía S, Galindo-Leal C. Monitoreo de las colonias de hibernación de mariposa Monarca: superficie forestall de ocupación en Dieciembre de 2005. Reporte de WWF. México D.F. 2005a;6pp.

28. Rendón-Salinas E, Rodríguez-Mejía S, Cruz-Piña M, Galindo-Leal C. Monitoreo de las colonias de hibernación de mariposa Monarca: superficie forestal de ocupación en Diciembre de 2006. Reporte de WWF. México D.F. 2006;6pp.

29. Rendón-Salinas E, Acevedo-Hernández N, Rodríguez-Mejía S, Galindo-Leal C. Monitoreo de las colonias de hibernación de mariposa Monarca: superficie forestal de ocupación en Diciembre de 2007. Reporte de WWF. México D.F. 2007;8pp.

30. Rendón-Salinas E, Valera-Bermejo CA, Martínez-Meza F. Monitoreo de las colonias de hibernación de mariposa Monarca: superficie forestal de ocupación en Diciembre de 2008. Reporte de WWF. México D.F. 2008;8pp.

31. Rendón-Salinas E, Valera-Bermejo CA, Rodríguez-Mejía S, Martínez-Meza F. Monitoreo de las colonias de hibernación de mariposa Monarca: superficie forestal de ocupación en Diciembre de 2009. Reporte de WWF. México D.F. 2009;8pp.

32. Rendón-Salinas E, Valera-Bermejo CA, Cruz-Piña M, Martínez-Meza F. Monitoreo de las colonias de hibernación de mariposa Monarca: superficie forestal de ocupación en Diciembre de 2010. Reporte de WWF. México D.F. 2010;8pp. 
33. Rendón-Salinas E, Rodríguez-Mejía S, Cruz-Piña M, Valera-Bermejo CA, Martínez-Meza F. Monitoreo de las colonias de hibernación de mariposa Monarca: superficie forestal de ocupación en Diciembre de 2011. Reporte de WWF. México D.F. 2011;8pp.

34. Rendón-Salinas, E, Tavera-Alonso G. Monitoreo de la superficie forestal ocupada por las colonias de hibernación de la mariposa Monarca en Diciembre de 2012. Reporte de WWF. México D.F. 2012;6pp.

35. Rendón-Salinas E, Tavera-Alonso G. Monitoreo de la superficie forestal ocupada por las colonias de hibernación de la mariposa Monarca en Diciembre de 2013. Reporte de WWF. México D.F. 2013;5pp.

36. Rendón-Salinas E, Fajardo-Arroyo A, Tavera-Alonso G. Superficie forestal ocupada por las colonias de hibernación de la mariposa Monarca en Diciembre de 2014. Reporte de WWF. México D.F. 2014;4pp.

37. Rendón-Salinas E, Martínez-Meza F, Fajardo-Arroyo A. Superficie forestal ocupada por las colonias de hibernación de la mariposa Monarca en Diciembre de 2015. Reporte de WWF. México D.F. 2015;3pp.

38. Rendón-Salinas E, Martínez-Meza F, Cruz-Piña M, Fajardo-Arroyo A. Superficie forestal ocupada por las colonias de hibernación de la mariposa Monarca en México en la temporada 2016-2017. Reporte de WWF. México D.F. 2016;3pp.

39. Rendón-Salinas E, Martínez-Meza F, Martínez-Pacheco A, Cruz-Piña M. Superficie forestal ocupada por las colonias de hibernación de la mariposa Monarca en México en la temporada 2017-2018. Reporte de WWF. México D.F. 2017;3pp.

40. Rendón-Salinas E, Martínez-Meza F, Mendoza-Pérez M, Cruz-Piña M, Mondragon-Contreras G, Martínez-Pacheco A. Superficie forestal ocupada por las colonias de hibernación de la mariposa Monarca en México en la temporada 2018-2019. Reporte de WWF. México D.F. 2018;4pp.

41. Rodda GH. The orientation and navigation of juvenile alligators: evidence of magnetic sensitivity. $J$ Comp Physiol A. 1984;154:649-658.

42. Fischer JH, Freake MJ, Borland SC, Phillips JB. Evidence for the use of magnetic map information by an amphibian. Anim Behav. 2001;62:1-10.

43. Boles LC, Lohmann KJ. True navigation and magnetic maps in spiny lobsters. Nature. 2003;421:6063.

44. Pittman SE, Hart KM, Cherkiss MS, Snow RW, Fujisaki I, Smith BJ, et al. Homing of invasive Burmese pythons in South Florida: evidence for map and compass senses in snakes. Biol. Lett. 2014;10:20140040.

45. Jorge PE, Almada F, Gonçalves AR, Duarte-Coelho P, Almada VC. Homing in rocky intertidal fish. Are Lipophrys pholis L. able to perform true navigation? Anim Cogn. 2012;15:1173-1181.

46. Freake MJ, Muheim R, Phillips JB. Magnetic maps in animals - a theory comes of age? Q Rev Biol. 2006;81:327-347.

47. Zhu S, Zhang W, Niitepõld K, Hsu J, Haeger JF, Zalucki MP, et al. The genetics of monarch butterfly migration and warning coloration. Nature. 2014;514:317-321. 
48. Billings J. Opening a window on Southwestern monarchs: fall migrant monarch butterflies, Danaus plexippus (L.), tagged synchronously in Southeastern Arizona migrate to overwintering regions in either Southern California or Central Mexico. J Lepid Soc. 2019;73:257-267.

49. Brower LP, Williams EH, Funk LS, Zubieta- Hernández RR, Ramirez MI. Monarch butterfly clusters provide microclimate advantages during the overwintering season in Mexico. J Lepid Soc. 2008;62:177-188.

50. Brower LP, Williams EH, Slayback DA, Fink LS, Ramirez MI, Zubieta RR, et al. Oyamel fir forest trunks provide thermal advantages for overwintering monarch butterflies in Mexico. Insect Conserv Diver. 2009;2:163-175.

51. Guerra PA, Reppert SM. Coldness triggers northward flight in remigrant monarch butterflies. Curr Biol. 2013;23:419-423.

52. Orley Jr OR, Lovett JP, Gibo DL, Weiser EL, Thogmartin WE, Semmens DJ, et al. Is the timing, pace, and success of the monarch migration associated with sun angle? Front Ecol Evol. 2019;7:442.

53. Honey-Rosés J. Disentangling the proximate factors of deforestation: the case of the monarch butterfly biosphere reserve in Mexico. Land Degrad Dev. 2009;20:22-32.

54. Vidal O, López-García J, Rendón-Salinas E. Trends in deforestation and forest degradation after a decade of monitoring in the Monarch Butterfly Biosphere reserve in Mexico. Conserv Biol. 2013;28:177-186.

55. Brower LP, Slayback DA, Jaramillo-López P, Ramirez I, Oberhauser KS, Williams EH, et al. Illegal logging of 10 hectares of forest in the Sierra Chincua monarch butterfly overwintering area in Mexico. Am Entomol. 2016;62:92-97.

\section{Figures}




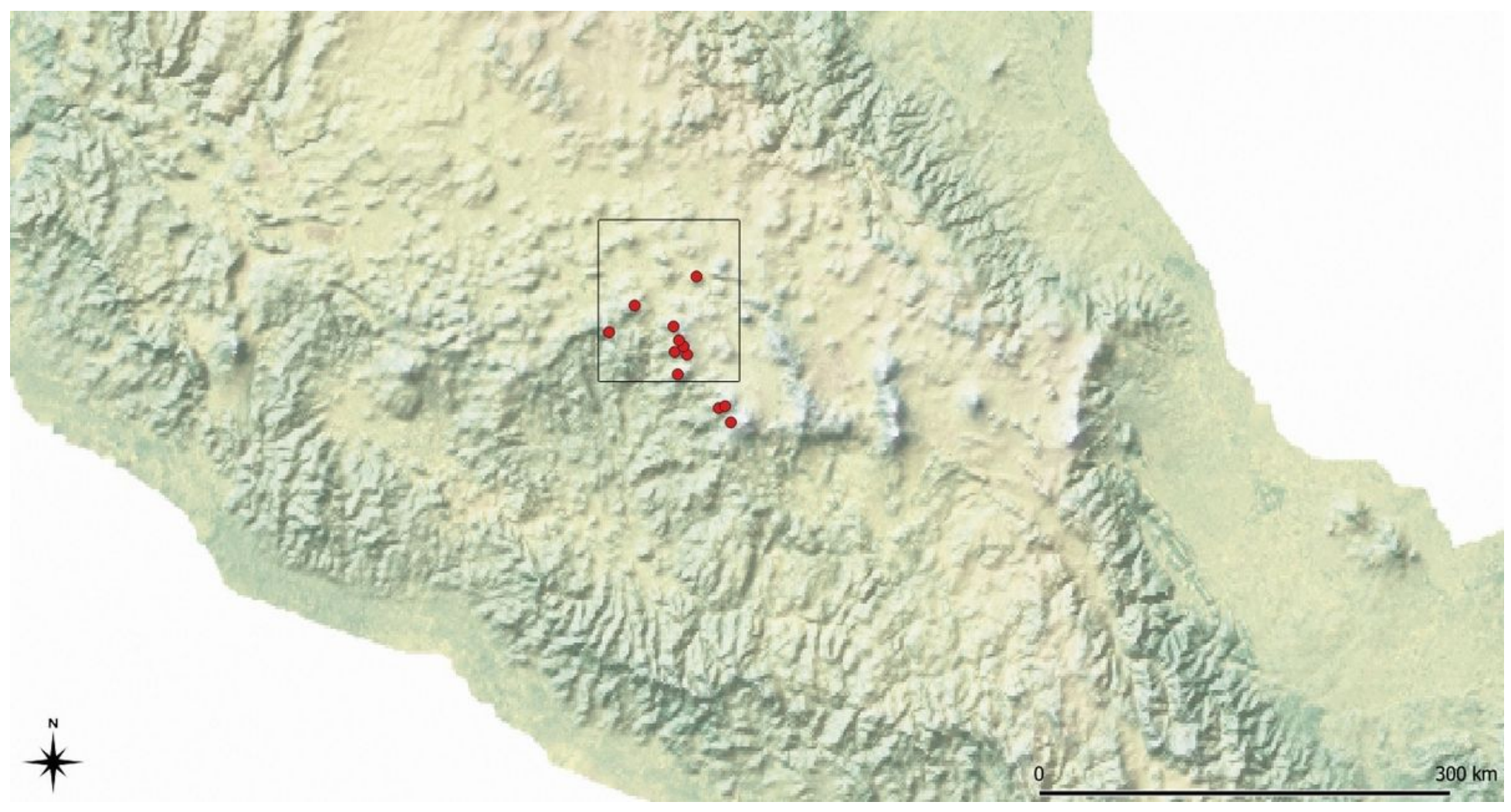

\section{Figure 1}

The location of monarch butterfly overwintering sites in Central Mexico. The black box projects the displacement of the observed range (2018) based on natural changes in the Earth's magnetic field since 2004. 




47.2047 .2547 .3047 .3547 .4047 .45

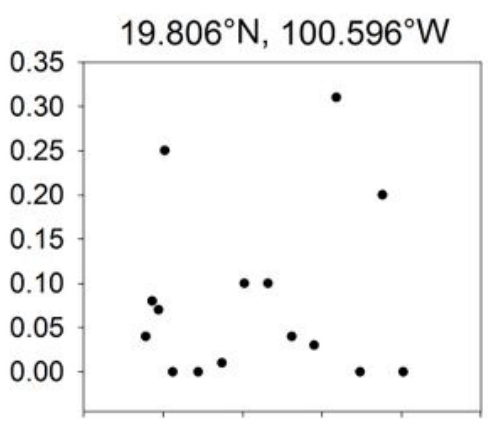

47.3047 .3547 .4047 .4547 .5047 .55

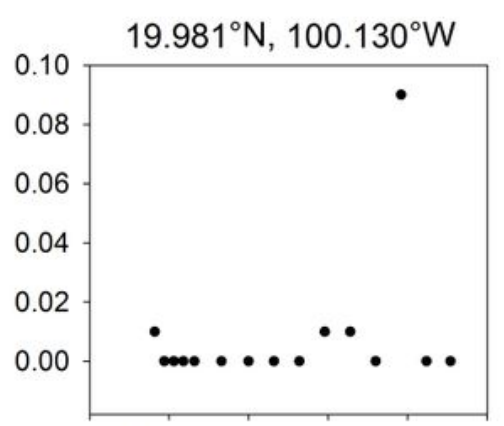

47.6047 .6547 .7047 .7547 .8047 .85

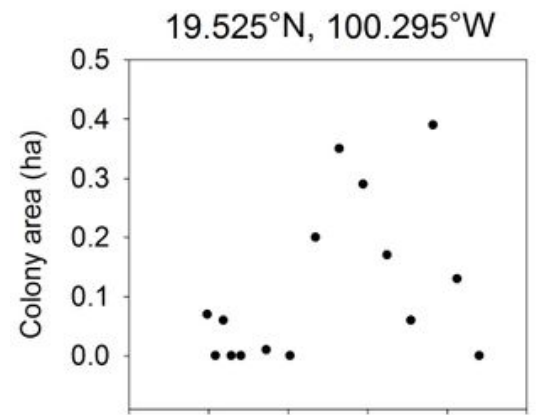

47.0047 .0547 .1047 .1547 .2047 .25

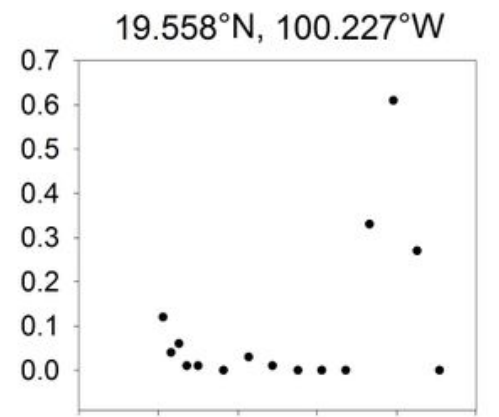

47.0547 .1047 .1547 .2047 .2547 .30

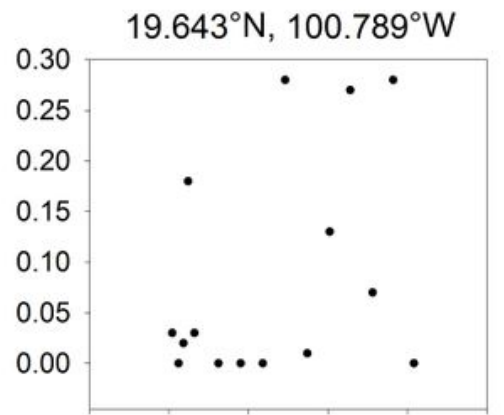

47.0547 .1047 .1547 .2047 .2547 .30



46.5546 .6046 .6546 .7046 .7546 .80

Magnetic inclination $\left({ }^{\circ}\right)$

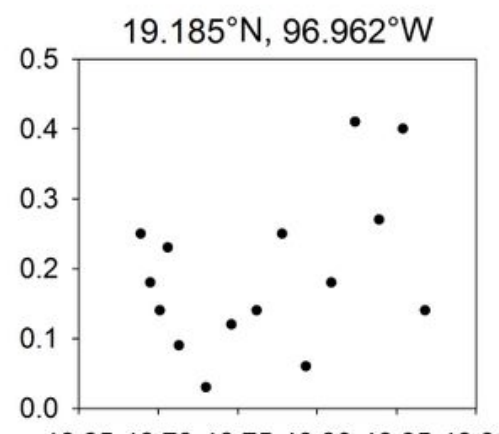

46.6546 .7046 .7546 .8046 .8546 .90

Magnetic inclination $\left({ }^{\circ}\right)$



46.7046 .7546 .8046 .8546 .9046 .95 Magnetic inclination $\left({ }^{\circ}\right)$

\section{Figure 2}

The relationship between colony size and the geomagnetic field inclination angle of overwintering sites. We examined the relationship between overwintering colony size of D. plexippus (ha) and the angle of inclination of the magnetic field for the three most southern overwintering sites. There was no relationship between colony size and magnetic inclination for these sites $(\beta=-1.00 \pm 0.80, t=-1.25, d f=1$, $p=0.23$, top; $\beta=0.73 \pm 0.46, t=1.58, d f=1, p=0.14$, middle; $\beta=-0.21 \pm 0.26, t=-0.79, d f=1, p=0.45$, 
bottom). The expectation is that if the butterflies use the magnetic field associated with the geographical location of overwintering sites as either magnetic map sense guide posts or as "homing beacon" cues, we should see a decline in abundance with decreasing angle of inclination, which is a positive slope in these analyses. Note that the scales differ among plots.

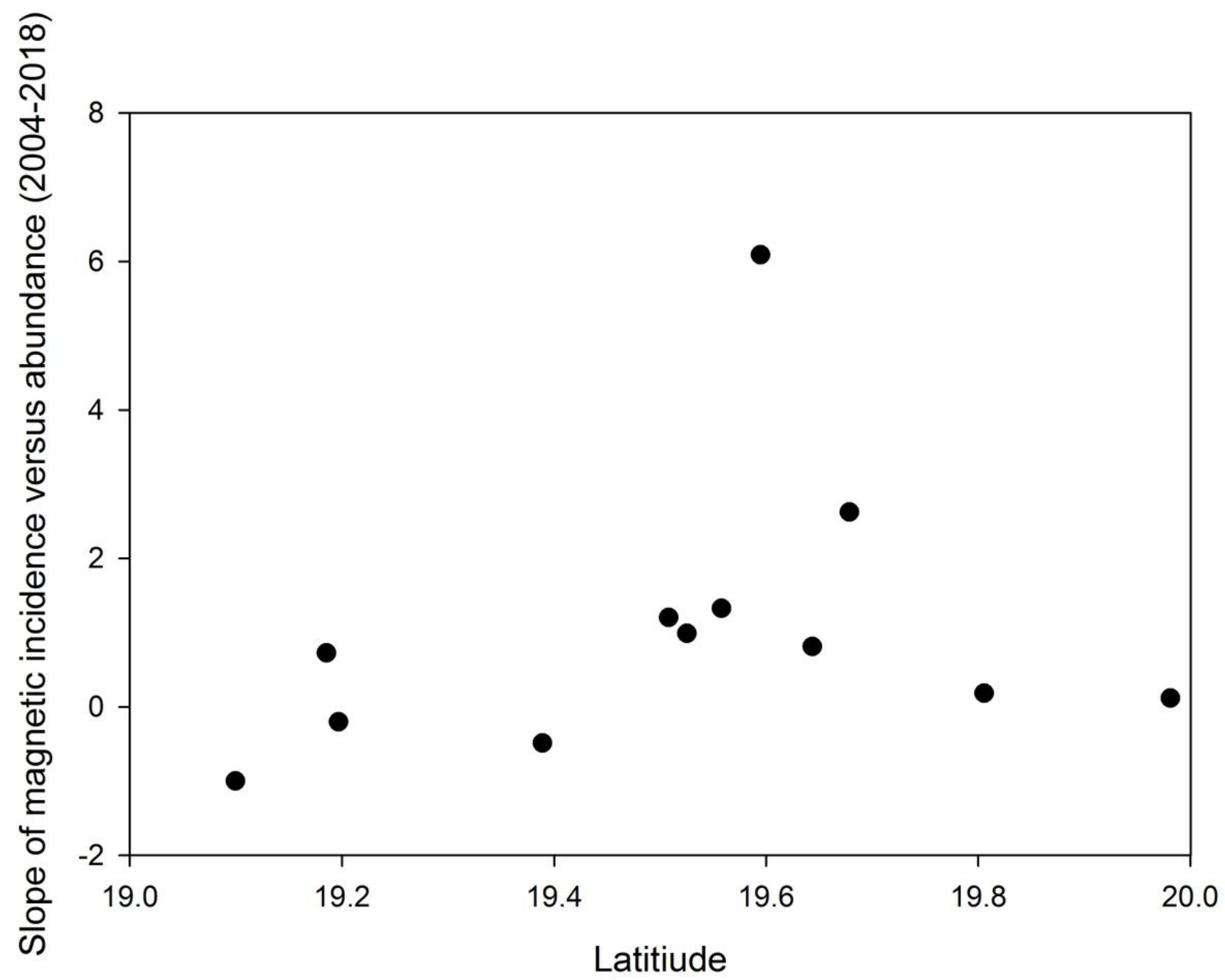

\section{Figure 3}

The slope of the relationship between colony size and geomagnetic inclination angle versus latitude. If monarchs were responding to the changing geomagnetic field, we would expect more southerly sites to have lower slopes (decreasing abundance) relative to more northerly sites. Thus, there should be a positive slope in this relationship; we found, however, that the slope was not significantly different than zero $(\beta=2.00 \pm 2.16, t=0.93, p=0.38)$. 